\title{
Guest Editorial: The FAMSUP network and its comparative studies of family support for frail older people
}

\author{
KAREN GLASER*, DOUGLAS A. WOLF $\dagger$ \\ and CECILIA TOMASSINI**
}

The aim of this special issue is to examine the relationships between support for older people and various socio-demographic, cultural and policy factors in selected European countries and the United States, using the international comparative perspective developed by the members of the Family Support for Older People: Determinants and Consequences (FAMSUP) network. Four of the included papers were delivered by network members at a symposium on 'Family Support for Older People: International Comparisons' that was held at the International Sociological Association (ISA) Inter-Congress Conference on Ageing Societies and Ageing Sociology: Diversity and Change in a Global World at the University of Surrey, Roehampton, in the suburbs of London (7-9 September 2004). Another paper, by Jim Ogg, a FAMSUP member, and Sylvie Renaut, investigates family networks among older people using data from the Survey of Health and Retirement in Europe (SHARE).

FAMSUP was supported by a grant from the European Science Foundation (ESF) during 2002-04. The network began when some members of the predecessor International Network for Research on Elder Care (INREC) identified a mutual interest in investigating the nature and determinants of support for older people across Europe, such as household composition and care provision. ${ }^{1}$ The initial members came from Austria, Germany, Italy, The Netherlands, Portugal, Sweden, United Kingdom and the United States, but the network has since expanded to include participants from many other countries. Emily Grundy of the Centre for Population Studies, London School of Hygiene and Tropical Medicine, is the network convenor. $^{2}$

The network's principal objectives were 'to examine the effect of demographic and family patterns ... on the likelihood of co-residence with an

* Institute of Gerontology, King's College London, London, UK.

$\dagger$ Center for Policy Research, Syracuse University, New York, USA.

** Department of Economic and Social Sciences, University of Molise, Campobasso, Italy. 
elderly parent and the provision of care, examine the effect of women's employment on the likelihood of co-residence with an elderly parent and the provision of care, investigate the relationship between material resources and the living arrangements of older people, analyse associations between living arrangements, especially living alone, and the health and wellbeing of older people in different countries, ... and examine interactions between the provision of family care and long-term care policies' ${ }^{3}$ To meet these objectives, five network meetings were held to discuss key concepts, data issues and relevant policy, and we collaborated in producing a cross-national meta-database to support comparative research. ${ }^{4}$ The FAMSUP meta-database has drawn on several nationallyrepresentative macro-level data sources, including: the Eurostat (Statistical Office of the European Communities) New Cronos database; the Eurobarometer surveys; Council of Europe publications on demographic developments in Europe; the US Census Bureau's International Data Base (IDB); and data from the International Labour Organisation (ILO). It also holds data from nationally-representative surveys, censuses and official publications provided by the members. ${ }^{5}$

The FAMSUP database has previously been used to investigate the variations in the living arrangements of older people during $1970-2000$ in Great Britain, The Netherlands, Sweden, the United States, Germany, Austria, Italy and Portugal (Tomassini et al. 2004). The analyses showed that all countries experienced an increase up to the early I9gos in the proportion of older people living alone, and that since, in most countries, the trend has slowed. Among older people who were not living alone or with a spouse, the most common living arrangements in southern Europe (Portugal and Italy) were living with offspring or in other arrangements, while in northern European countries (Sweden and The Netherlands), the most frequent arrangement was residential care. The remaining countries (Great Britain, Germany, US and Austria) were in intermediate positions. The analysis also examined variations and trends in demographic, socioeconomic and cultural factors, such as divorce, women's employment, fertility, and attitudes towards inter-generational co-residence. There were large differences in attitudes toward residential care and co-residence, but little change in attitudes over time, and again the greatest differences were between the northern and the southern pairs of countries, with the other countries in between. Finally, the study considered to what degree differences in demographic, socio-economic and cultural factors and trends explained the national variations in living arrangements. The stabilisation, or even decrease, in the proportion aged 65 or more years who were living alone in many countries is probably explained by the increase in the proportion of married individuals and by later childbearing. 
There is growing evidence that differences in cultural values help to explain national differences in residential care and in co-residence.

A subsequent paper addressed the demographic, cultural and policy dimensions of elder care among the studied countries (Glaser, Tomassini and Grundy 2004). The aim of that paper was to explore the north-south divide in various dimensions associated with support for older people. Commentators have recently distinguished 'weak' from 'strong' family societies, and argued that less family-oriented societies provide relatively little support for family members, including elderly relatives, whereas in southern European countries with strong family ties, family support is stronger. To examine this hypothesis, the study used principal components analysis and cluster analysis to investigate the patterns on four dimensions of the balance between family and formally-provided resources for older people. The paper also discussed the socio-economic, demographic and policy contexts in which care is provided. The results showed that rather than a clear-cut north-south division, when a wide range of measures associated with different dimensions of support for older people is considered, more complex variations in patterns of support for older people are found among European countries. A third paper has also drawn on the meta-database and considered, from theoretical and empirical perspectives, the sources of vulnerability in elderly populations in Europe and the possible policy responses (Grundy 2006).

Apart from working together on this research agenda, the FAMSUP members are committed to fostering more mutual learning among researchers in Europe. The network has therefore collaborated with the European Association for Population Studies (EAPS) in organising a 'network of networks' meeting in Paris in September 2004. This brought together representatives from over 20 cross-national European groups undertaking research on closely-related topics, many of whom were unaware of each other's activities (for more details see Glaser 2004).

\section{NOTES}

I For more details of INREC, visit http://www-cpr.maxwell.syr.edu/inrec/

2 The network members in May 2006 were: Marjolein Broese van Groenou (Department of Sociology and Social Gerontology, Vrije Universiteit Amsterdam, The Netherlands); Ewa Fraczak (Institute of Statistics and Demography, Warsaw School of Economics, Poland); Karen Glaser (Institute of Gerontology, King's College London, UK); Cristina Gonçalves (Portuguese National Statistics Institute (INE), Department of Census and Population Studies, Lisbon, Portugal); Thérèse Jacobs (General Director, Population and Family Study Centre, Brussels, Belgium); Jim Ogg (Direction des Recherches sur le Viellissement, Caisse Nationale d'Assurance Vieillesse, Paris, France); Ulrike Schneider (Institute for Social Policy, 
Department of Economics, Vienna University of Economics and Public Administration, Vienna, Austria); Norbert Neuwirth (Department for Socio-Economic Analysis, Österreichisches Institut für Familienforschung, Vienna, Austria); Martin Spielauer (Max Planck Institute for Demographic Research, Rostock, Germany); Katharina Spiess (German Socio-economic Panel Study (SOEP), German Institute for Economic Research (DIW Berlin), Berlin, Germany); Gerdt Sundström (Institute of Gerontology, Jönköping University, Sweden); Cecilia Tomassini (Department of Economic and Social Sciences, University of Molise, Campobasso, Italy); and Douglas Wolf (Centre for Policy Research, Syracuse University, New York, USA).

3 Extracts from the FAMSUP website: see http://www.lshtm.ac.uk/cps/famsup/ GOALS.htm [Accessed 6 July 2005].

4 The meetings were held in Hanover, Germany (February 2002), Strasbourg, France (July 2002), London (May 2003), Warsaw (August 2003) and Roehampton, near London (September 2004).

5 Access to the New Cronos database is limited to subscribers at http://europa.eu.int/ newcronos Eurobarometer survey data are accessible at http://europa.eu.int/comm/ public_opinion/. The US Census Bureau database is accessible at http://www. census.gov/ipc/www/idbnew.html

\section{References}

Glaser, K. 2004. European Association for Population Studies Working Group on Demographic Change and Care of Older People/Institut National d'Études Démographiques: European networks and projects. European fournal of Ageing, I, IO2-5.

Glaser, K., Tomassini, C. and Grundy, E. 2004. Revisiting convergence and divergence: support for elderly people in Europe. European Fournal of Ageing, I, 64-72.

Grundy, E. 2006. Ageing and vulnerable elderly people: European perspectives. Ageing E Society, 26, 105-34.

Tomassini, C., Glaser, K., Wolf, D. A., Broese van Groenou, M. I. and Grundy, E. 2004. Living arrangements among older people: an overview of trends in Europe and the USA. Population Trends, I I 5, 24-34.

Address for correspondence:

Accepted 3 May 2006

Karen Glaser, Institute of Gerontology, King's College London,

Waterloo Bridge Wing, Franklin-Williams Building, Waterloo Road, London SEi 9NH.

E-mail: karen.glaser@kcl.ac.uk 